\title{
Performance of Novel Randomly Oriented High Graphene Carbon in Lithium Ion Capacitors
}

\author{
Rahul S. Kadam (D) and Kishor P. Gadkaree \\ Corning Incorporated, 1 Science Drive, Painted Post, NY 14870, USA \\ Correspondence should be addressed to Rahul S. Kadam; kadamrs@corning.com
}

Received 17 August 2017; Accepted 23 January 2018; Published 1 March 2018

Academic Editor: Jili Li

Copyright (C) 2018 Rahul S. Kadam and Kishor P. Gadkaree. This is an open access article distributed under the Creative Commons Attribution License, which permits unrestricted use, distribution, and reproduction in any medium, provided the original work is properly cited.

\begin{abstract}
The structure of carbon material comprising the anode is the key to the performance of a lithium ion capacitor. In addition to determining the capacity, the structure of the carbon material also determines the diffusion rate of the lithium ion into the anode which in turn controls power density which is vital in high rate applications. This paper covers details of systematic investigation of the performance of a structurally novel carbon, called Randomly Oriented High Graphene (ROHG) carbon, and graphite in a high rate application device, that is, lithium ion capacitor. Electrochemical impedance spectroscopy shows that ROHG is less resistive and has faster lithium ion diffusion rates $\left(393.7 \times 10^{-3} \mathrm{~S} \cdot \mathrm{s}^{(1 / 2)}\right)$ compared to graphite $\left(338.1 \times 10^{-3} \mathrm{~S} \cdot \mathrm{s}^{(1 / 2)}\right)$. The impedance spectroscopy data is supported by the cell data showing that the ROHG carbon based device has energy density of $22.8 \mathrm{Wh} / \mathrm{l}$ with a power density of $4349.3 \mathrm{~W} / \mathrm{l}$, whereas baseline graphite based device has energy density of $5 \mathrm{Wh} / \mathrm{l}$ and power density of $4243.3 \mathrm{~W} / 1$. This data clearly shows advantage of the randomly oriented graphene platelet structure of ROHG in lithium ion capacitor performance.
\end{abstract}

\section{Introduction}

Batteries are the ubiquitous energy storage devices. However, batteries, although high in energy density, do not have adequate power for many applications. Electric double layer capacitors (EDLCs) have been developed to address this need for high power devices. The usage of EDLCs is growing exponentially. However, EDLCs have high power but low energy [1-3]. For many applications, there is a need for next generation devices which have significantly higher energy and power densities. To address the problems of EDLC of lack of high energy density and in a lithium ion battery of lack of high power density, lithium ion capacitors (LICs), a new class of innovative hybrid energy storage devices is advancing rapidly and has been commercialized recently [4]. As the hybrid of two different energy storage mechanisms, EDLC and lithium ion battery, lithium ion capacitor displays energy density intermediate between the lithium ion battery (LIBs) and EDLCs but has higher power than lithium ion battery. Unlike EDLCs which store energy based on double layer mechanism on both electrodes or lithium ion battery which stores energy based on faradaic mechanism on both the electrodes, the lithium ion capacitors store energy on the cathode via nonfaradaic mechanism (double layer mechanism), whereas energy storage on anode constructed from low surface area carbon is via faradaic mechanism. As a result, the energy density in such devices can be threefold to fourfold of EDLC, and power is also threefold to fourfold the lithium ion battery $[1-3,5-10]$. These devices still show very high cycle life, in excess of 1 million cycles compared to lithium ion batteries which are limited to 300-400 cycles, making them attractive for many applications $[8,11]$.

In a lithium ion capacitor, the negative electrode (intercalating and deintercalating) is predoped with lithium metal (lithium metal foil or lithium powder). The predoping of the lithium ion capacitor allows increase in the operating voltage to approximately about 3.8 volts, whereas in EDLC the operating voltage is 2.7 to 3 volts. The predoping of the anode with lithium occupies partial storage capacity of the electrode. Theoretically, the predoped lithium should remain in the anode during the charged and discharged state of the capacitor. During the charging and discharging process, the 
anode electrode is the kinetically rate limiting electrode due to the faradaic process occurring during charge and discharge process $[8,12]$. Since the lithium ion capacitor is a power device, it is critical to measure the material performance at high charge-discharge rates (C-rates) to select optimum material especially for the rate limiting anode electrode. Unlike batteries which operate at 1C, capacitor operates at rates in excess of $100 \mathrm{C}$. Anode materials with high capacity but low diffusion rate will yield poor power performance. For lithium ion capacitors, the anode carbon should have the following properties.

(1) High Reversible Capacity and Lower Irreversible Capacity. Reversible capacity measures the amount of lithium which can be intercalated and deintercalated reversibly. This reversible capacity determines the usable energy available in the capacitor.

(2) Fast Lithium Ion Diffusion. To deliver high power, the fast and efficient intercalation and deintercalation of the ions in the kinetically rate limiting anode electrode are necessary.

Using lithium ion battery as precedence, researchers have utilized graphite as the anode material in lithium ion capacitor applications $[8,12]$. The intercalation and deintercalation of lithium ion happen between the parallel graphene platelets during charge and discharge process. In this case, the distance between two graphene platelets is close to $0.34 \mathrm{~nm}$ [13-15]. However, the kinetics of intercalation and deintercalation of lithium ion in graphite is too slow for it to be used as an anode material in lithium ion capacitor [7]. Hard carbon materials, that is, nongraphitic materials with low surface area, have also been evaluated as anode materials in lithium ion capacitors. Due to the structural alterations in the hard (nongraphitic) carbon, no solvent cointercalation is observed and this increases the solvent choice as an electrolyte. Nongraphitic carbons also show higher capacities compared to graphitic carbon. However, although hard carbon materials have very high initial capacities, one of the main issues with using hard carbon materials is the very high irreversible capacity. High irreversible capacity leads to loss of lithium and hence low performance and higher cost of the device $[8,16]$. Because of this problem, hard carbon is generally not used in LIC devices.

To this effect, we have earlier reported in detail the systematic investigation of the thermodynamics (entropy and enthalpy) of intercalation associated with lithium ion in a structurally novel carbon, called Randomly Oriented High Graphene (ROHG) carbon, and compared it to graphite [17]. The study clearly shows that a lower amount of energy is required for the lithium ion intercalation into the ROHG structure compared to graphite structure. Randomly oriented graphene platelet cluster structure of ROHG carbon makes it easier for the intercalation or deintercalation of lithium ion. In this article, we will discuss the application of ROHG carbon as anode intercalating material for high rate applications such as a working lithium ion capacitor and will be compared to a lithium ion capacitor with commercially available graphite as anode material.

\section{Experimental}

2.1. Anode Materials and Construction. ROHG carbon was obtained from a natural carbon precursor via heat treatment in inert environment at temperatures above $1000^{\circ} \mathrm{C}$ [18]. Graphite powder (Timcal (Model TB-17)) and Timcal SuperC45 carbon black was acquired from MTI Corporation and used as it is. KYNAR 761 grade PVDF and N-methyl pyrrolidinone was obtained from Arkema Chemicals Company and Sigma Aldrich, respectively. The anode electrodes consisted of $90 \%$ carbon (graphite or ROHG), 5\% carbon black, and 5\% PVDF. 3.6 grams of carbon and 0.2 grams of carbon black were ball-milled for 10 minutes at $350 \mathrm{rpm}$ in Retsch PM100. 0.2 grams of PVDF was added to the ballmilled mixture and ball-milled for another 10 minutes at $350 \mathrm{rpm} .5 \mathrm{ml}$ of NMP (N-methyl pyrrolidinone) was added to the carbon, carbon black, and PVDF mixture and ballmilled for 10 minutes at $350 \mathrm{rpm}$ to yield a viscous slurry mixture. The slurry mixture was coated on a copper foil (product number: Oak-Mitsui TLB-DS) acquired from OakMitsui using the Mayer rod coating method (rod number: $50 \mathrm{G}$ ). The coated electrodes were dried under vacuum at $50^{\circ} \mathrm{C}$. The dried electrodes were punched into discs of $14 \mathrm{~mm}$, dried under vacuum at $120^{\circ} \mathrm{C}$ for 12 hours, and stored under Argon atmosphere in a glove box.

2.2. Cathode Materials and Construction. Cathode carbon was synthesized in house and prepared from natural carbon precursor via chemical activation and heat treatment in inert environment at temperatures close to $700-800^{\circ} \mathrm{C}$ [19]. The electrodes consisted of $92.5 \%$ cathode carbon (3.7 grams), $2.5 \%$ carbon black (0.1 grams), and 5\% PVDF (KYNAR HSV 900) (0.2 grams). Identical ball-milling procedure was followed as described in the anode material and construction section (Section 2.1) except for $11 \mathrm{ml}$ of NMP (N-methyl pyrrolidinone) which was added to the slurry. The slurry mixture was coated on a TOYO aluminum foil acquired from Oak-Mitsui. The TOYO aluminum foil was pretreated with $5 \%$ sodium naphthalenide/diglyme solution. The electrodes were coated using the Mayer rod coating method (rod number: $160 \mathrm{G}$ ) and dried under vacuum at $120^{\circ} \mathrm{C}$. The electrodes were punched, dried, and stored as explained in Section 2.1.

2.3. Lithium Metal Composite Powder (LCP). LCP was synthesized in the laboratory according to the procedure described previously in the literature [20]. The LCP is comprised of $80 \%$ lithium metal coated with $20 \%$ lithium based salts. The LCP was used to predope the anode electrode with lithium metal.

2.4. Construction of Half Cell. Half cells (coin cells) were built with carbon (ROHG or graphite) electrodes and lithium metal disc as the counter electrodes. Polyethylene based separator was used to separate the two electrodes. $120 \mu \mathrm{l}$ of 1.2 M LiPF6 in 20:20:60 ethylene carbonate: dimethyl carbonate: methyl propionate (volumetric), and $5 \mathrm{wt} \%$ fluoroethylene carbonate were used as an electrolyte. The cells were conditioned with two slow ( C/30 rate) chargedischarge cycles on Arbin. 


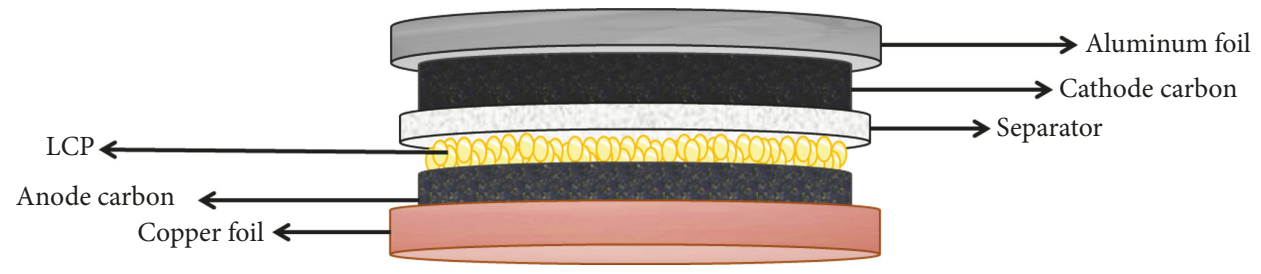

FIGURE 1: Schematic of coin cell assembly.

2.5. Construction and Testing of Working Lithium Ion Capacitor. Lithium ion capacitor coin cells were built and all the cells were tested at $25^{\circ} \mathrm{C}$. A schematic of coin cell assembly is shown in Figure 1. All the cells were built with $1 \mathrm{M} \mathrm{LiPF}_{6}$ in ethylene carbonate (EC)/dimethyl carbonate (DMC)/methyl propionate (MP) with 5\%/weight of fluoroethylene carbonate (FEC) as electrolyte. The cathode was placed in an aluminum clad bottom can. A cellulosic separator (Nippon Kodoshi Corporation (NKK) TF4425 Separator) was placed over the cathode. 3.5 milligrams of LCP was weighed on the separator. The negative electrode was placed on the lithium metal composite powder. All the cells were conditioned on Arbin BT 2000 with 5 cycles at constant current of 0.0004 Amperes charge and discharge schedule from $2.2 \mathrm{~V}$ to $3.8 \mathrm{~V}$. The cells were subjected to constant voltage hold at $3.8 \mathrm{~V}$ for 1 hour between charge and discharge cycles at 0.0004 Amperes.

The conditioned lithium ion capacitors were subjected to Electrochemical Impedance Spectroscopy (EIS) measurement on Gamry potentiostat/galvanostat instrument at $3.8 \mathrm{~V}$ (charged state). The EIS measurement was done by applying a sinusoidal (AC) current between frequencies from $0.01 \mathrm{~Hz}$ to $100000 \mathrm{~Hz}$.

The cells were subjected to $C$ rate testing where the cells were charged at $0.001 \mathrm{~A}$ and discharged at different $\mathrm{C}$-rates (1 C, 5 C, 10 C, 20 C, 50 C, 100 C, and 200 C).

\section{Results}

3.1. Intercalation Curves from Half Cell. We have reported earlier $\mathrm{Li}$ ion intercalation curves for graphite and $\mathrm{ROHG}$ carbon [17] (Figure 2).

From the intercalation curves, it is evident that there is a difference in the lithium intercalation mechanism between ROHG and graphite. We had demonstrated that the different features associated with progression in lithium intercalation in the concentration as a function of voltage plot indicate that different lithium compounds are present in ROHG compared to graphite. The intercalation curves show that graphite has higher lithium ion intercalation deintercalation capacity than $\mathrm{ROHG}$ at $\mathrm{C} / 30$ rate. At $100 \%$ lithiation, graphite has a " $x$ " value of 0.823 , whereas ROHG carbon shows a " $x$ " value of 0.764 . However, ROHG carbon, due to its unique structure, is more suitable for high rate applications [17] and its performance in a full working lithium ion capacitor is discussed in detail in the following sections.

3.2. Conditioning of the Working Lithium Ion Capacitor. Conditioning of the cells assures a thorough wetting of the electrodes with the electrolyte and a formation of a

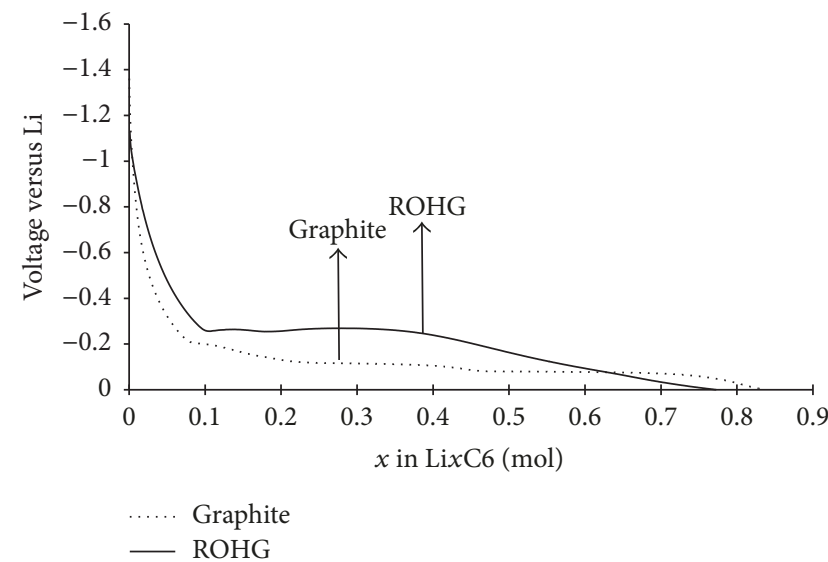

FIGURE 2: Plot of moles of $\mathrm{Li}$ as a function of voltage with reference to Li metal.

stable Solid Electrolyte Interphase (SEI). During the initial conditioning cycle, there are irreversible reactions of lithium and solvent (electrolyte) with the carbon surface which forms a SEI. The SEI plays an important role in protecting the electrolyte from further contact with the reactive carbon surface and undergoing unwanted reactions in the cell. The SEI also is responsible for the long-term stability (aging) of the cell. The extent of irreversible reactions depends on surface and structure of carbon. Once the ions take part in the irreversible reactions, these ions are lost and do not contribute to energy storage. Hence, the anode carbon needs to be tailored to reduce irreversible reactions [21, 22].

The conditioning cycles were carried out at approximately $\mathrm{C} / 2$ rate. Figures 3 and 4 represent the conditioning and efficiency data for ROHG carbon and graphite.

After 5 cycles of conditioning, graphite and ROHG show comparable discharge capacity of 112.6 (Table 1) and $108.9 \mathrm{mAh} / \mathrm{gm}$ (Table 2), respectively. The discharge capacity is normalized with the weight of the anode carbon. ROHG and graphite also show comparable charge-discharge efficiencies after 5 cycles. The efficiencies in both the cases are above 95\% after 5 conditioning cycles. Since the first conditioning cycle shows $\sim 93 \%$ efficiency in both the cases, only $7 \%$ of the total lithium ions are irreversibly lost probably to the formation of SEI (solid electrolyte interphase) on the anode electrode. The irreversible capacities on graphite and ROHG are comparable and low.

3.3. Electrochemical Impedance Spectroscopy. Figure 5 shows the electrochemical impedance spectra (EIS) for ROHG carbon and graphite based lithium ion capacitor in charged 
TABLE 1: Discharge capacity and efficiency for graphite.

\begin{tabular}{lcc}
\hline Cycle number & Discharge capacity $(\mathrm{mAh} / \mathrm{gm})$ & Efficiency\% \\
\hline$(1)$ & 103.8 & 92.8 \\
$(2)$ & 108.2 & 89.4 \\
$(3)$ & 110.8 & 92.6 \\
$(4)$ & 112.4 & 95.2 \\
$(5)$ & 112.6 & 96.4 \\
\hline
\end{tabular}

TABLE 2: Discharge capacity and efficiency for ROHG.

\begin{tabular}{lcc}
\hline Cycle & Discharge capacity $(\mathrm{mAh} / \mathrm{gm})$ & Efficiency\% \\
\hline$(1)$ & 96.0 & 92.6 \\
$(2)$ & 101.7 & 91.3 \\
$(3)$ & 105.4 & 93.8 \\
$(4)$ & 108.1 & 95.8 \\
$(5)$ & 108.9 & 95.4 \\
\hline
\end{tabular}

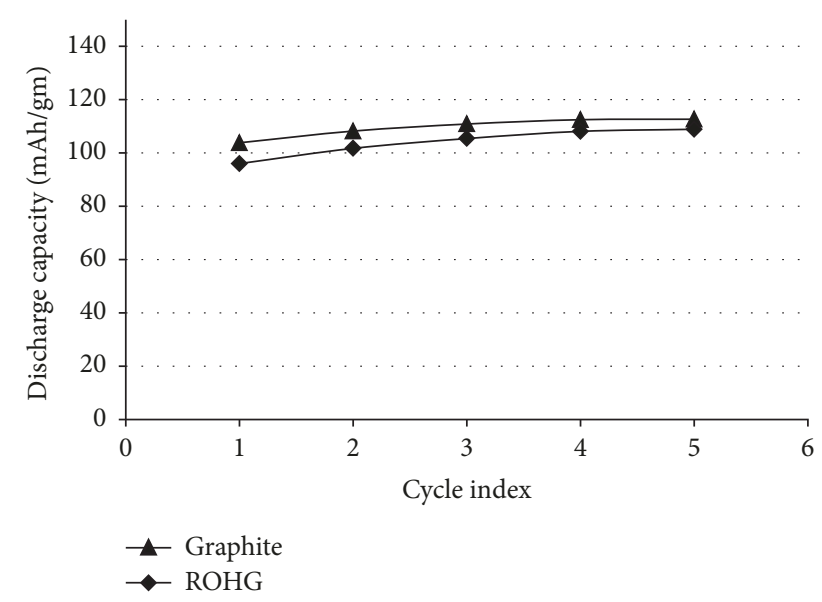

FIGURE 3: Weight normalized discharge capacity for conditioning cycles as a function of cycle index.

state at $3.8 \mathrm{~V}$. The EIS curves were fitted to an equivalent circuit model as shown in Figure 6.

The model consists of three different components. A resistor $R_{s}$ is connected in series to another circuit which consist of $R_{\mathrm{SEI}}$ and $C_{\mathrm{SEI}}$ in parallel which is connected in series to another circuit which consist of $R_{\mathrm{ct}}$ in series with Warburg element $(W)$ and parallel to a constant phase element (CPE). $R_{s}$ corresponds to contact resistance between various parts of the cell, $R_{\mathrm{SEI}}$ corresponds to resistance from the solid electrolyte interface, $R_{\mathrm{ct}}$ corresponds to charge transfer resistance, and $W$ corresponds to Warburg element which is influenced by the diffusion impedance of the lithium ions. The impedance spectrum for ROHG and graphite shows a single semicircle at high and mid frequencies which includes $R_{s}, R_{\mathrm{SEI}}$, and $R_{\mathrm{ct}}$ together. The $45^{\circ}$ line at low frequency is the Warburg element and shows the diffusion impedance of the lithium ions [23].

Figure 5 shows that graphite based cell shows combined impedance $\left(R_{s}, R_{\mathrm{SEI}}\right.$, and $\left.R_{\mathrm{ct}}\right)$ of $3.6 \mathrm{ohms}$ compared to ROHG which shows $2.6 \mathrm{ohms}$. It is well known that,

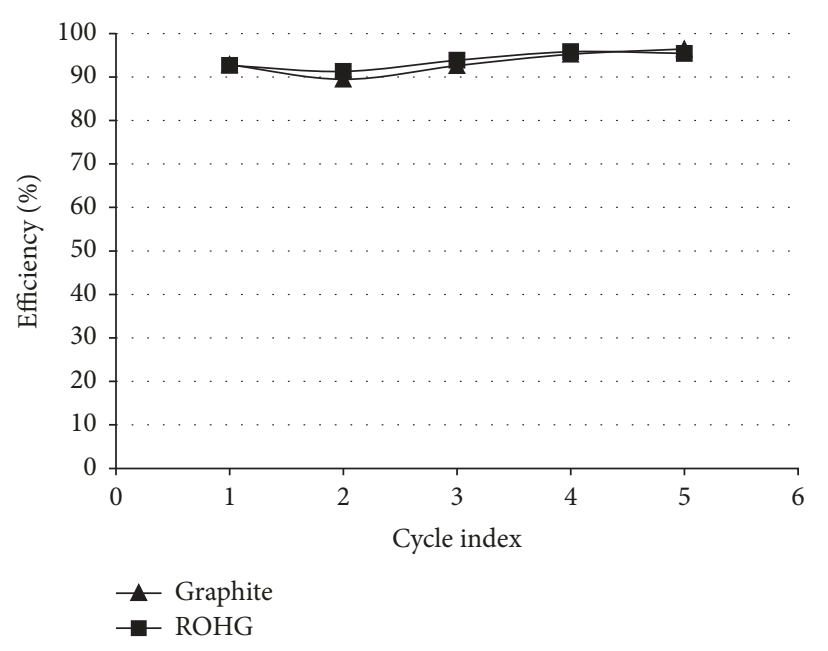

FIGURE 4: Efficiency (\%) data of graphite and ROHG as a function of conditioning cycles.

in lithium cells with intercalation electrodes, the Warburg element represents the diffusion of lithium ions through the electrodes. ROHG and graphite diffusion rates are $393.7 \times$ $10^{-3} \mathrm{~S} \cdot \mathrm{s}^{(1 / 2)}$ and $338.1 \times 10^{-3} \mathrm{~S} \cdot \mathrm{s}^{(1 / 2)}$, respectively. The ROHG carbon shows lower overall impedance values compared to graphite. The diffusion of lithium ions through the ROHG based anode is thus expected to be much faster than in graphite based anode.

3.4. Ragone Plot. Figure 7 shows the Ragone plot for a full cell device based on Corning processed ROHG carbon [18] and graphite anodes.

The Ragone plot shows that the ROHG carbon shows superior performance at all tested rates (1 C-200 C). However, the plot shows that where graphite does not retain energy densities at higher power, ROHG retains power at high rates. For example, at high rate of $100 \mathrm{C}$, the ROHG carbon shows an energy density of $22.8 \mathrm{Wh} / \mathrm{l}$ with a power density of $4349.3 \mathrm{~W} / \mathrm{l}$, whereas graphite shows an energy 


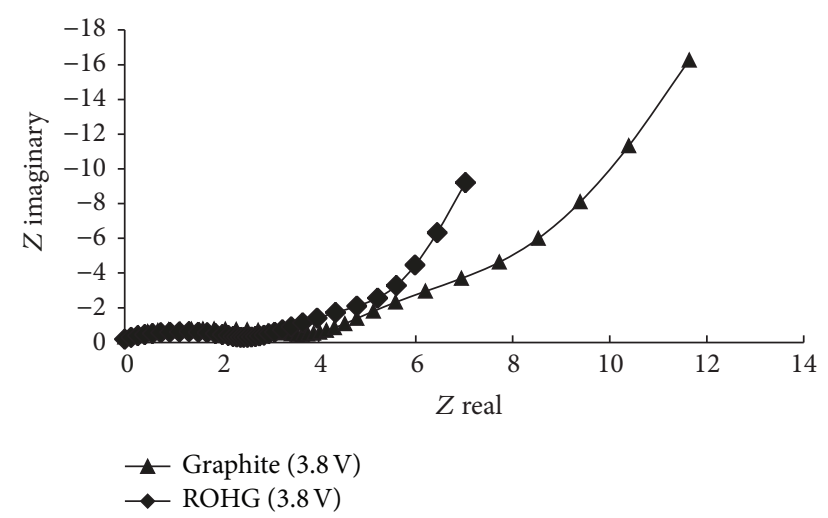

FIGURE 5: Electrochemical impedance spectra for ROHG and graphite (at $3.8 \mathrm{~V}$ ).

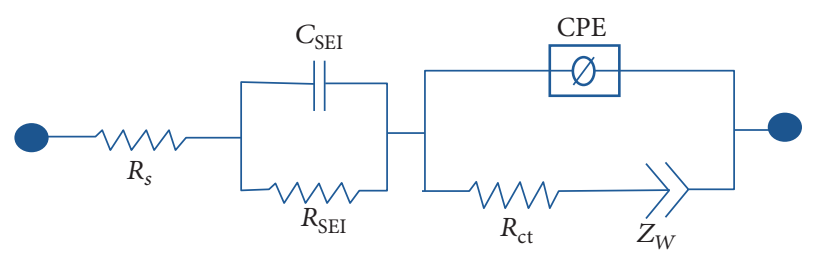

FIGURE 6: Equivalent circuit model for EIS curves.

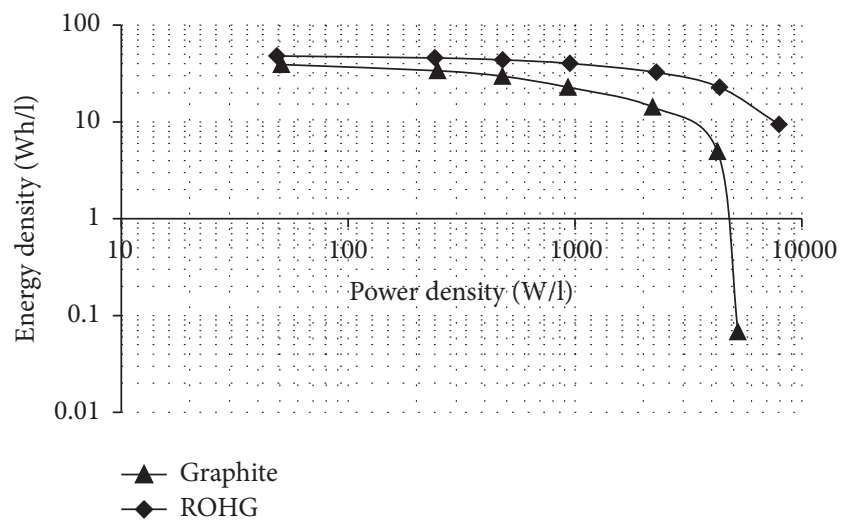

FIGURE 7: Ragone plot for Corning temperature processed hard carbon and graphite.

density of $4.9 \mathrm{Wh} / \mathrm{l}$ with a power density of $4243.3 \mathrm{~W} / \mathrm{l}$. The ROHG carbon delivers higher energy density at a given power density compared to graphite based anodes in lithium ion capacitor. Since LICs are high rate device and applications are in the rates of $100 \mathrm{C}$ or higher, the ROHG based device will provide severalfold higher energy density than standard graphite based LIC. This advantage will not only make ROHG based device much more attractive in LIC applications but may allow new applications which are beyond capabilities of today's LICs.

\section{Discussion}

We had earlier published the structure of ROHG carbon and predicted the mechanism of intercalation and deintercalation of lithium ion in ROHG carbon based on the thermodynamic study and Monte Carlo simulations. Figure 8 shows the predicted structure of ROHG carbon and Figure 9 shows the intercalation model [17].

Based on the Monte Carlo simulation, we have established that the ROHG carbon consists of cluster of convoluted and randomly oriented graphene platelets at high concentration as opposed to organized parallel graphene platelets in graphite (Figure 10). The ROHG carbon is synthesized by treating the precursor/raw material above $1000^{\circ} \mathrm{C}$. The higher temperature $\left(>1000^{\circ} \mathrm{C}\right)$ increases graphene platelet area and reduces edges by forming more convoluted structures. The higher crystallinity due to increase in graphene platelet area gives more surface area to reversibly react, thus increasing the reversible capacity at higher C-rates. Also, a reduction in edge sites is observed, thus reducing the irreversible capacity at higher rates. Figures 11(a) and 11(b) show the X-ray diffraction patterns for ROHG and graphite, respectively. Figure 12 shows the comparison of irreversible capacities at $100 \mathrm{C}$ rate for graphite and ROHG carbon. Hard carbons treated at lower temperatures $\left(<1000^{\circ} \mathrm{C}\right)$ show lower crystallinity and high irreversible capacity.

The spacing between graphene platelets in ROHG is wider compared to graphite. We have proved a lithium ion intercalation model where the lithium insertion takes place in between the cluster of convoluted and randomly oriented graphene platelets. During the first stage of intercalation, the lithium ion is at the shallow end of the graphene platelets. Further intercalation allows the lithium ion to be inserted deep into the graphene platelets of the ROHG [16]. The established structural and intercalation model complements the observations from impedance spectroscopy and Ragone plot reported in this article.

At slower rates (conditioning rates $\sim \mathrm{C} / 2$ ), graphite and ROHG show comparable conditioning efficiencies and discharge capacities. However, it is evident from the Ragone plot that the amount of lithium ion intercalated and deintercalated (energy density) and energy density retention is higher in ROHG carbon at higher C-rates in a working lithium ion capacitor compared to graphite. Along with the high crystallinity of ROHG, the wide spacing between the convoluted graphene platelets in ROHG makes the intercalation and deintercalation of lithium ions easy and fast in the ROHG based anode, thus showing higher energy density and better energy density retention compared to graphite based lithium ion capacitor. To complement the Ragone plot, the impedance spectra show that the ROHG carbon is inherently less resistive and shows diffusion of lithium ions in the electrode which is much faster compared to graphite. Based on the observations, ROHG qualifies to be a more desirable anode carbon material for high rate applications such as lithium ion capacitors.

\section{Conclusion}

ROHG carbon was tested as an anode carbon material for a high rate application: that is, lithium ion capacitor and its performance were compared to commercially available and widely used graphite material. The ROHG carbon and 


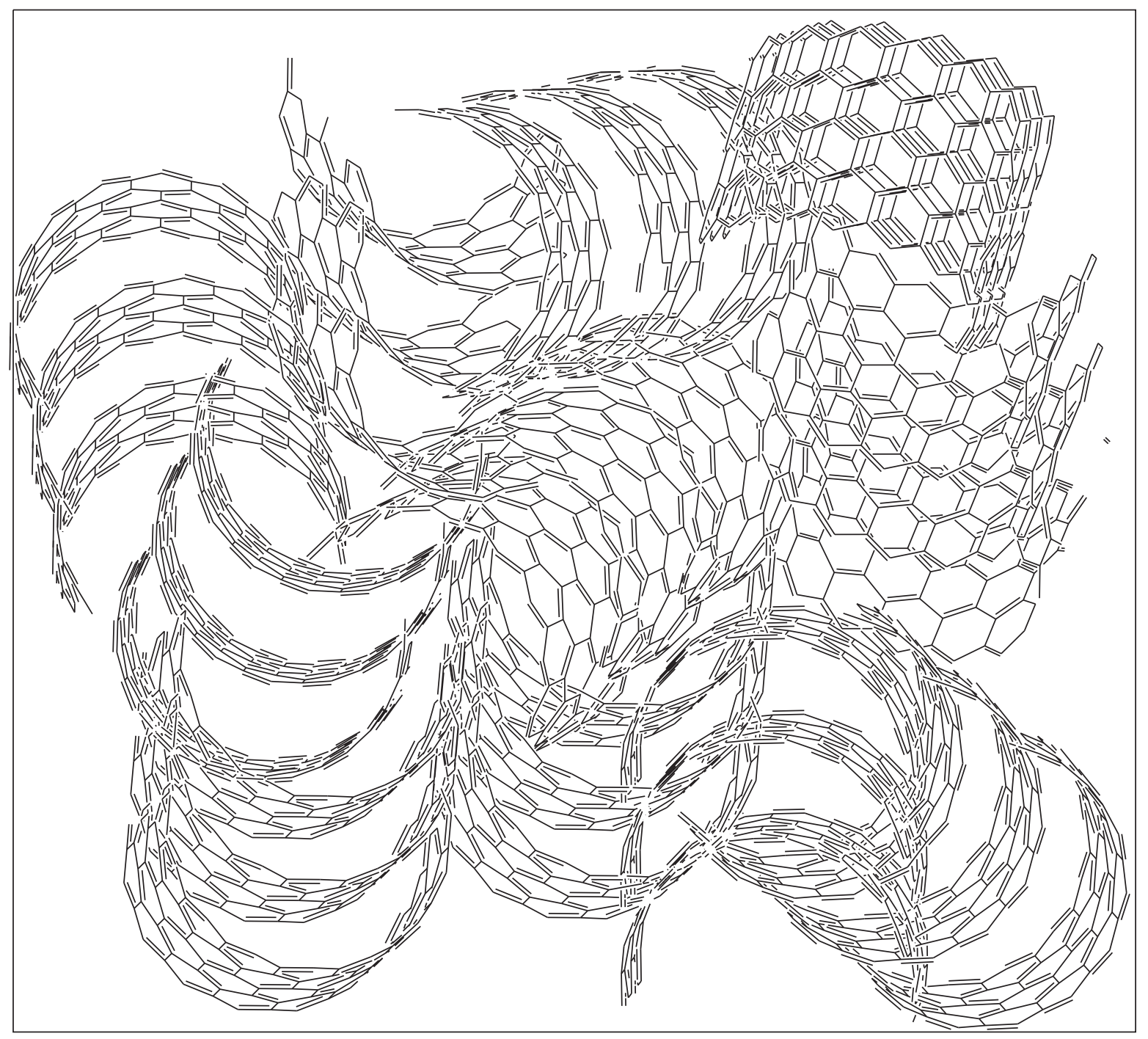

FIGURE 8: Structure and morphology of ROHG based on Monte Carlo simulations.
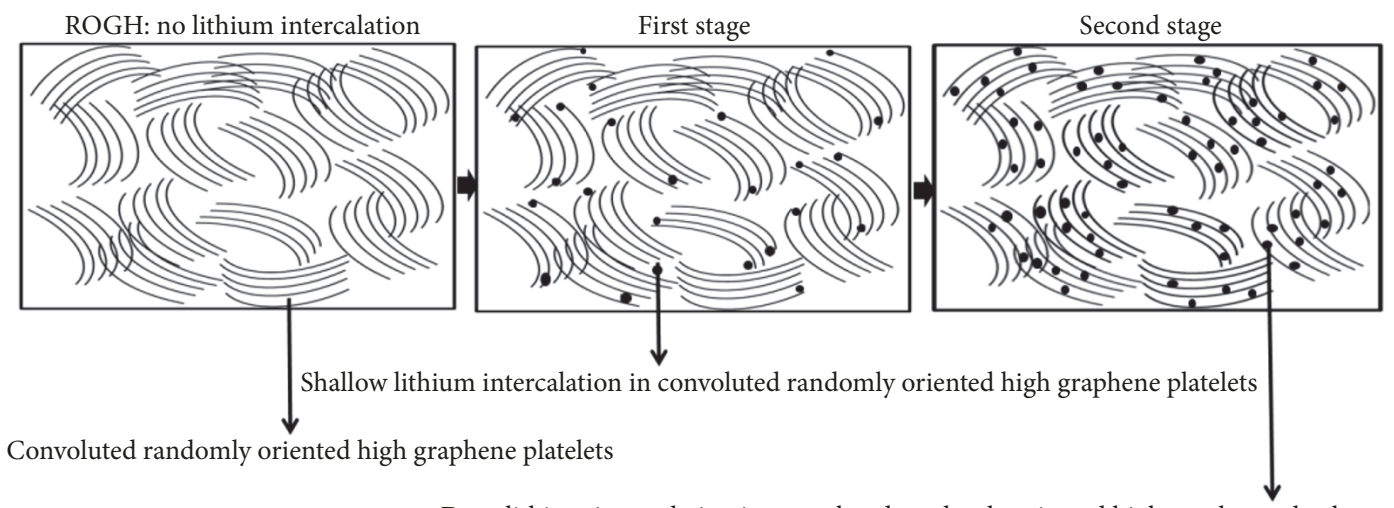

Deep lithium intercalation in convoluted randomly oriented high graphene platelets

Figure 9: Predicted model for different stages of lithium intercalation in ROHG. 


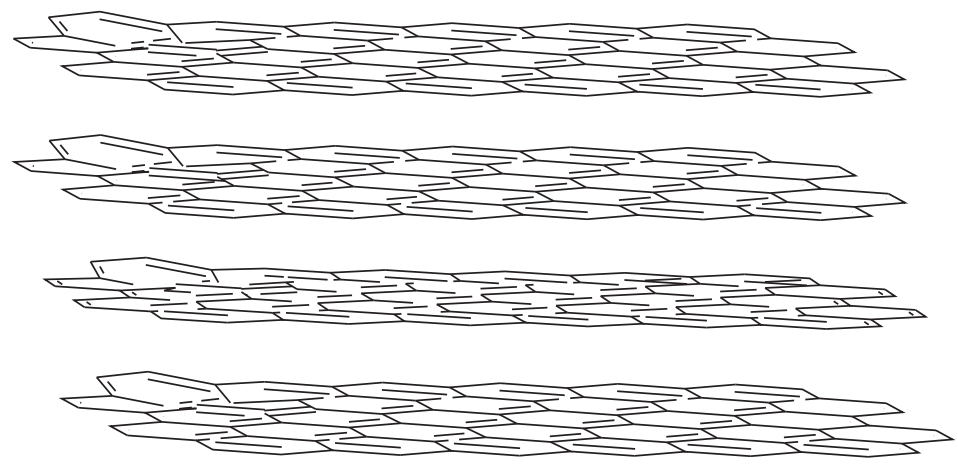

FIGURE 10: Structure and morphology of graphite.

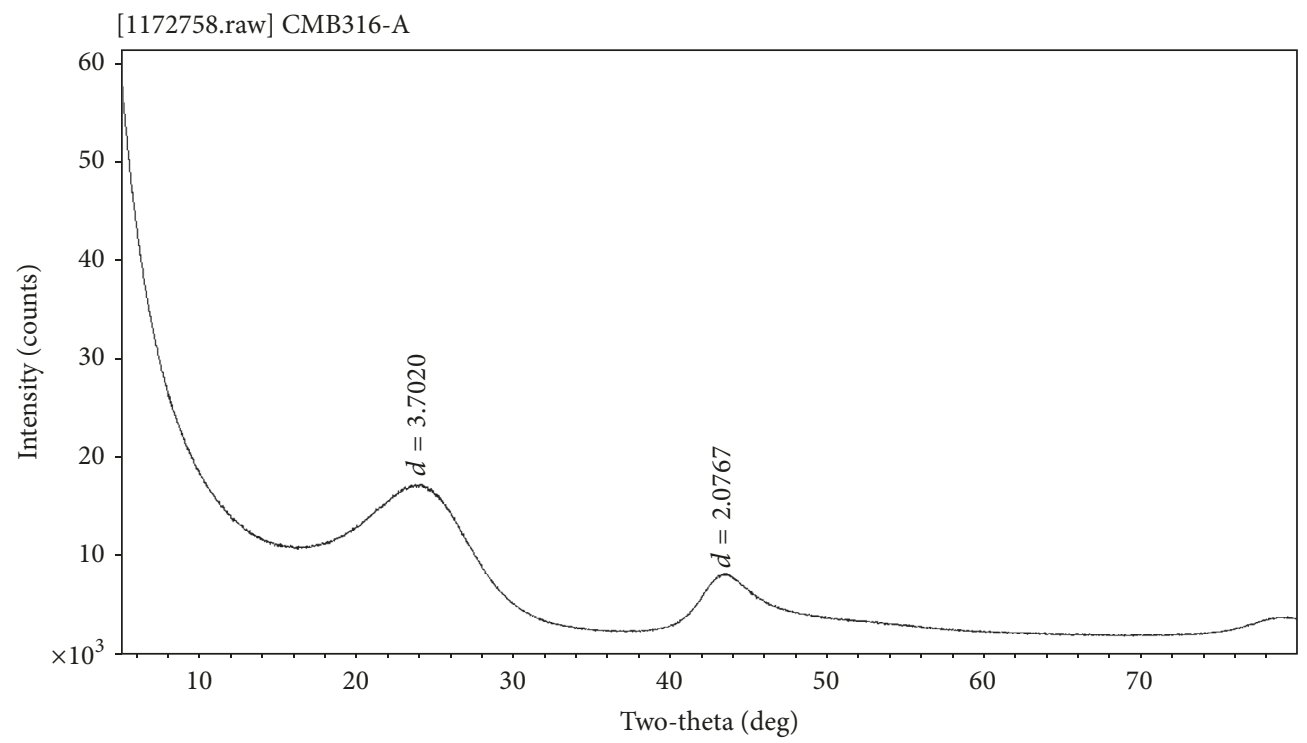

(a) X-ray diffraction pattern for ROHG carbon

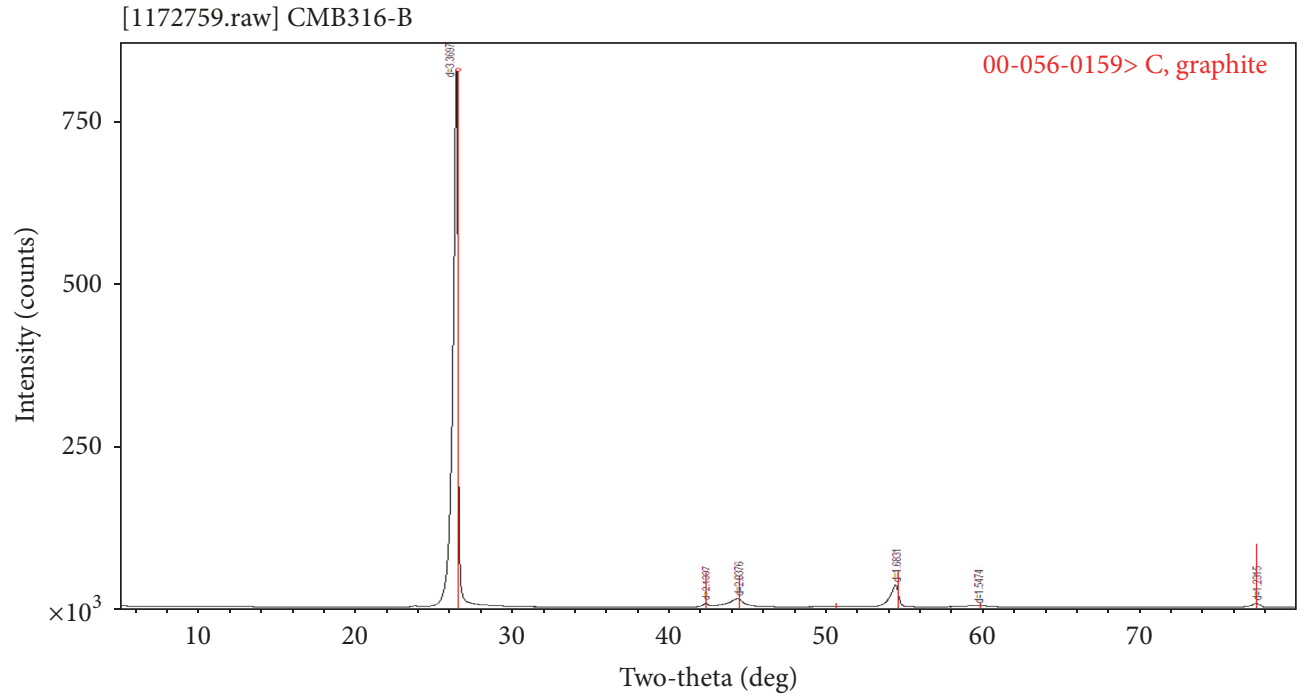

(b) X-ray diffraction pattern for graphite

Figure 11 


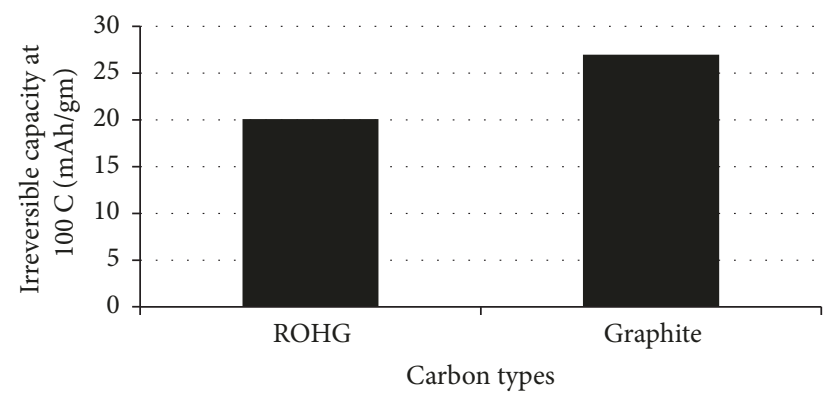

FIGURE 12: Comparison of irreversible capacities at $100 \mathrm{C}$ rate.

graphite show low and comparable irreversible capacity at conditioning rates $(\sim \mathrm{C} / 2)$. ROHG and graphite both show excellent overall efficiency of $\sim 95 \%$ after five conditioning cycles at lower rates. The conditioning discharge capacities for ROHG at lower rates are comparable to graphite and could be a potential candidate for anode carbon for slow rate applications such as lithium ion batteries also because of the low cost. The impedance spectroscopy shows that ROHG carbon is less resistive and shows lower diffusional impedance for transport of lithium ions through the carbon structure compared to graphite. This observation is further reinforced by the Ragone plot (energy density as a function of power density) of the full cell LIC, where ROHG show a superior energy density output for a given power density at all tested rates from $1 \mathrm{C}$ to $200 \mathrm{C}$. At slower rates, the ROHG carbon shows an energy density of $48.55 \mathrm{Wh} / 1$ with a power density of $48.03 \mathrm{~W} / \mathrm{l}$ compared to graphite which shows an energy density of $50.95 \mathrm{Wh} / \mathrm{l}$ with a power density of $39.16 \mathrm{~W} / 1$. However, at higher rates $(100 \mathrm{C})$, the ROHG carbon shows an energy density of $22.8 \mathrm{Wh} / 1$ with a power density of $4349.3 \mathrm{~W} / \mathrm{l}$, whereas graphite shows an energy density of $4.9 \mathrm{Wh} / 1$ with a power density of 4243.3 W/1. The superior performance of ROHG to graphite, especially at higher rates, is due to the unique structure. ROHG has randomly oriented graphene platelets cluster structure of the ROHG carbon compared to the parallel long graphene platelets structure in graphite. These structural differences between ROHG and graphite are responsible for the ROHG superior performance at high rates.

\section{Abbreviations}

ROHG: Randomly Oriented High Graphene Carbon

SEI: $\quad$ Solid electrolyte interphase

LIB: Lithium ion battery

LIC: Lithium ion capacitor

EDLC: Electric double layer capacitor.

\section{Conflicts of Interest}

The authors declare that there are no conflicts of interest regarding the publication of this paper.

\section{Acknowledgments}

This work was supported by Corning Incorporated. Help from Mr. Andrew Husted and Ms. Catherine Burdick in fabrication of devices and cell testing is gratefully acknowledged.

\section{References}

[1] G. Wang, L. Zhang, and J. Zhang, "A review of electrode materials for electrochemical supercapacitors," Chemical Society Reviews, vol. 41, pp. 797-828, 2012.

[2] R. Kötz and M. Carlen, "Principles and applications of electrochemical capacitors," Electrochimica Acta, vol. 45, no. 15-16, pp. 2483-2498, 2000.

[3] P. Simon and Y. Gogotsi, "Materials for electrochemical capacitors," Nature Materials, vol. 7, no. 11, pp. 845-854, 2008.

[4] J. Ronsmans and B. Lalande, "Combining energy with power: Lithium-Ion Capacitors," in Proceedings of the 2016 International Symposium on Power Electronics, Electrical Drives, Automation and Motion, SPEEDAM 2016, pp. 261-264, Italy, June 2016.

[5] J. B. Goodenough and K.-S. Park, "The Li-ion rechargeable battery: a perspective," Journal of the American Chemical Society, vol. 135, no. 4, pp. 1167-1176, 2013.

[6] N. Nitta, F. Wu, J. T. Lee, and G. Yushin, "Li-ion battery materials: present and future," Materials Today, vol. 18, no. 5, pp. 252-264, 2015.

[7] K. Xu, "Electrolytes and interphases in Li-ion batteries and beyond," Chemical Reviews, vol. 114, no. 23, pp. 11503-11618, 2014.

[8] S. R. Sivakkumar and A. G. Pandolfo, "Evaluation of lithiumion capacitors assembled with pre-lithiated graphite anode and activated carbon cathode," Electrochimica Acta, vol. 65, pp. 280 $287,2012$.

[9] M. Risa, H. Yukinori, I. Masako, I. Koji, and S. Daisuke, "Development of high-power lithium-ion capacitor," NEC Technical Journal, vol. 5, no. 4, pp. 52-56, 2010.

[10] W. J. Caoa and J. P. Zheng, "Li-ion capacitors using carboncarbon electrodes," ECS Transactions, vol. 45, no. 29, pp. 165172, 2013.

[11] M. Schroeder, M. Winter, S. Passerini, and A. Balducci, "On the cycling stability of lithium-ion capacitors containing soft carbon as anodic material," Journal of Power Sources, vol. 238, pp. 388-394, 2013.

[12] M. Yuan, W. Liu, Y. Zhu, and Y. Xu, "Electrochemical performance of pre-lithiated graphite as negative electrode in lithiumion capacitors," Russian Journal of Electrochemistry, vol. 50, no. 11, pp. 1050-1057, 2014.

[13] L. C. Pardini, F. L. Neto, and J. L. D. A. Fereira, "Damping behavior of synthetic graphite beams," Materials Research, vol. 9, no. 2, pp. 193-197, 2006.

[14] J. R. Dahn, R. Fong, and M. J. Spoon, "Suppression of staging in lithium-intercalated carbon by disorder in the host," Physical Review B: Condensed Matter and Materials Physics, vol. 42, no. 10, pp. 6424-6432, 1990.

[15] D. Billaud, F. X. Henry, and P. Willmann, "Electrochemical synthesis of binary graphite-lithium intercalation compounds," Materials Research Bulletin, vol. 28, no. 5, pp. 477-483, 1993.

[16] J. Zhang, X. Liu, J. Wang, J. Shi, and Z. Shi, "Different types of pre-lithiated hard carbon as negative electrode material for lithium-ion capacitors," Electrochimica Acta, vol. 187, pp. 134142, 2016.

[17] R. S. Kadam and K. P. Gadkaree, "Thermodynamics of lithium intercalation in randomly oriented high graphene carbon," 
International Journal of Electrochemistry, vol. 2017, Article ID 5391794, 6 pages, 2017.

[18] K. Gadkaree and R. Kadam, "Anode for lithium ion capacitor, US Patent 9,552,930, 2017”.

[19] K. Gadkaree, R. Kadam, and J. Liu, Cathode for a lithium ion capacitor, US Patent 9,679,704, 2017.

[20] K. Gadkaree and X. Liu, Stabilized lithium composite particles, US Patent 8,920,925 B2, 2014.

[21] D. M. Seo, D. Chalasani, B. S. Parimalam, R. Kadam, M. Nie, and B. L. Lucht, "Reduction reactions of carbonate solvents for lithium ion batteries," ECS Electrochemistry Letters, vol. 3, no. 9, pp. A91-A93, 2014.

[22] M. Nie, D. Chalasani, D. P. Abraham, Y. Chen, A. Bose, and B. L. Lucht, "Lithium ion battery graphite solid electrolyte interphase revealed by microscopy and spectroscopy," The Journal of Physical Chemistry C, vol. 117, no. 3, pp. 1257-1267, 2013.

[23] X. Gao, C. Zhan, X. Yu et al., "A high performance lithium-ion capacitor with both electrodes prepared from Sri Lanka graphite ore," Materials , vol. 10, no. 4, article no. 414, 2017. 

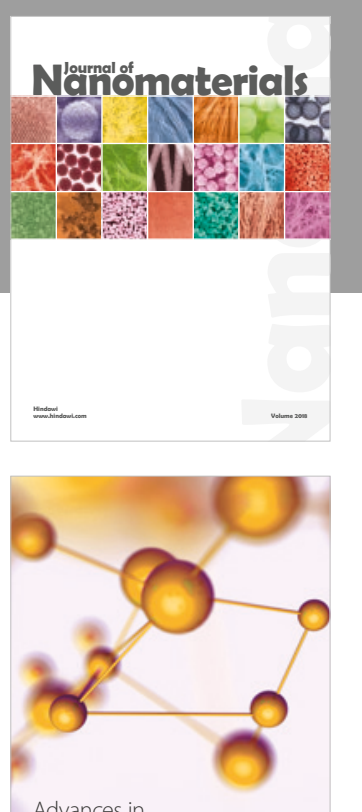

Physical Chemistry
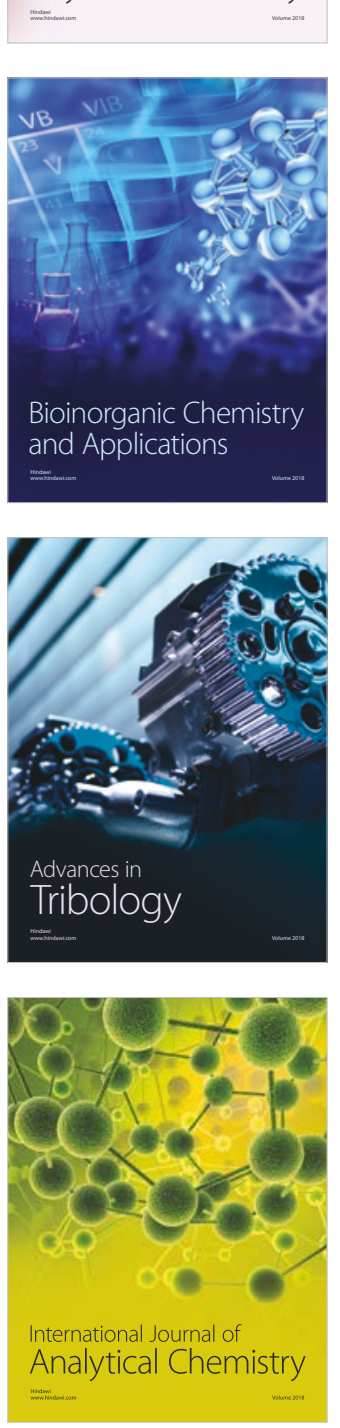

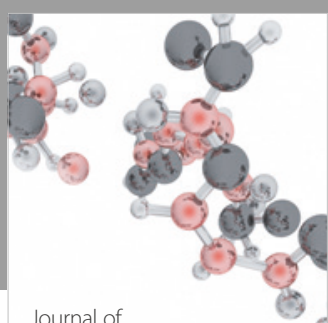

Analytical Methods

in Chemistry

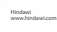

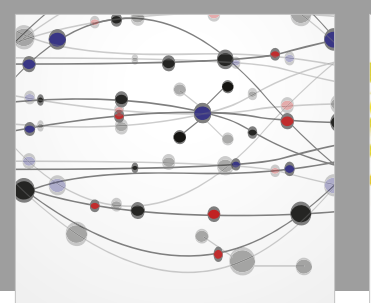

The Scientific World Journal

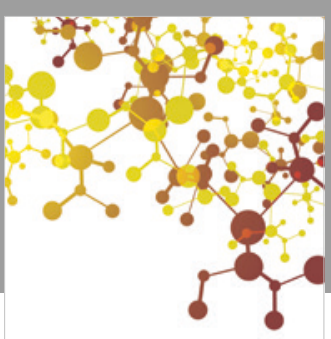

Journal of

Applied Chemistry
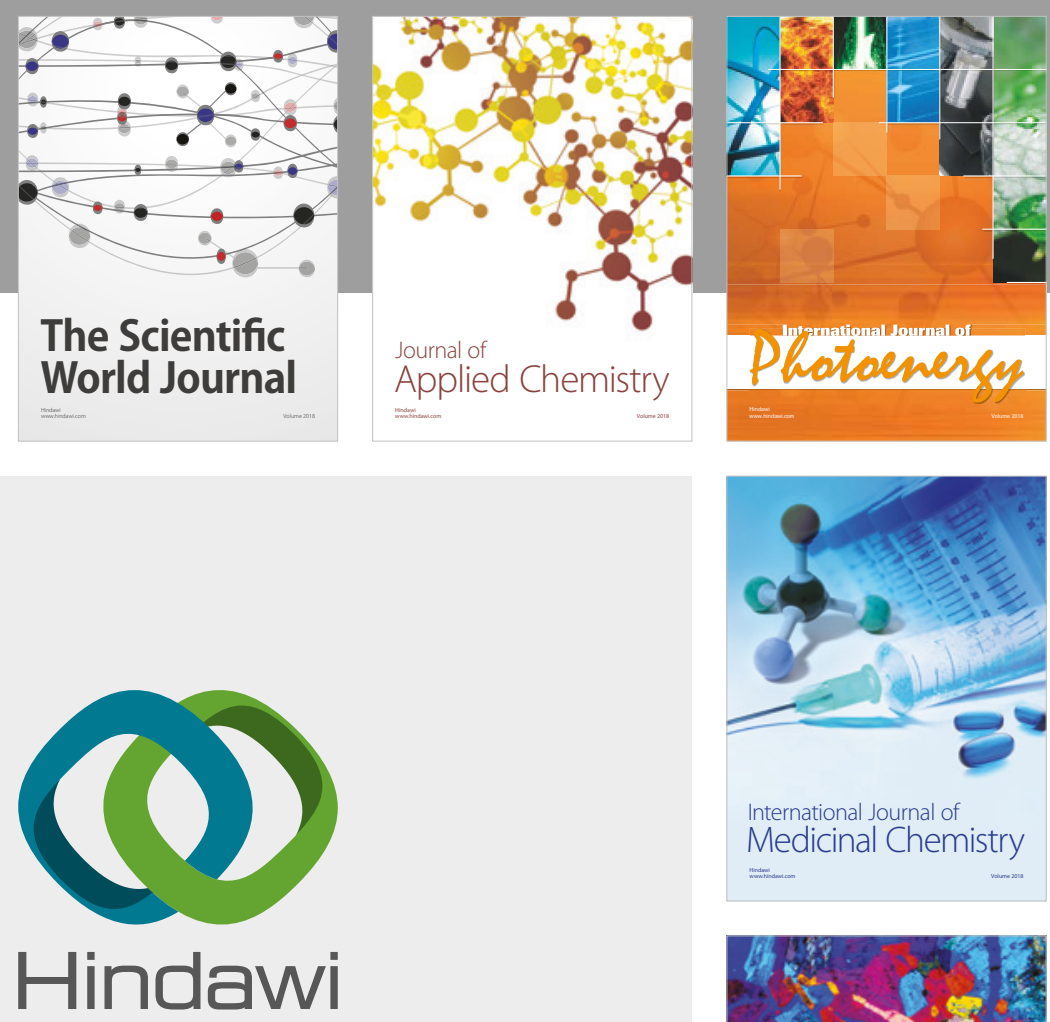

Submit your manuscripts at

www.hindawi.com
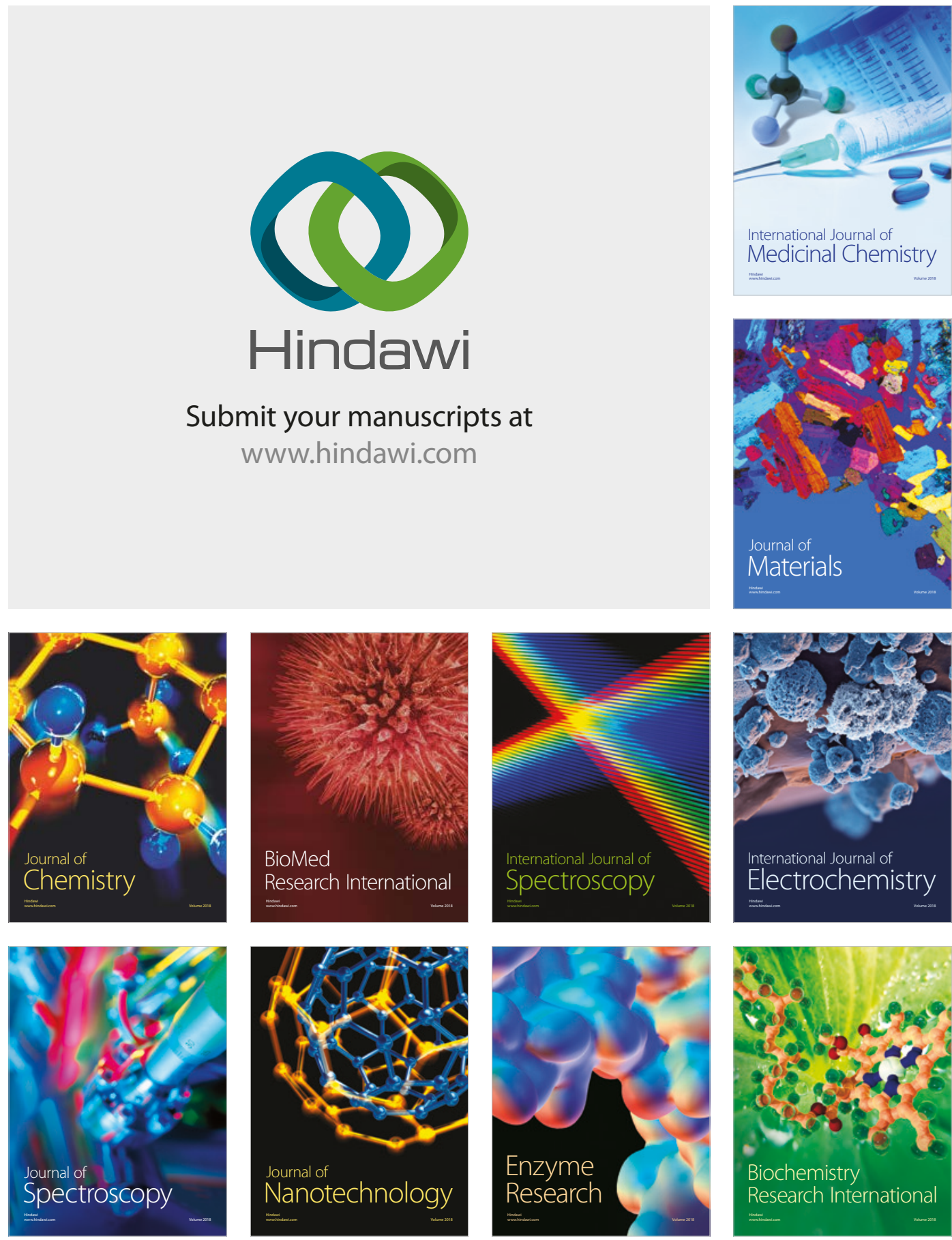
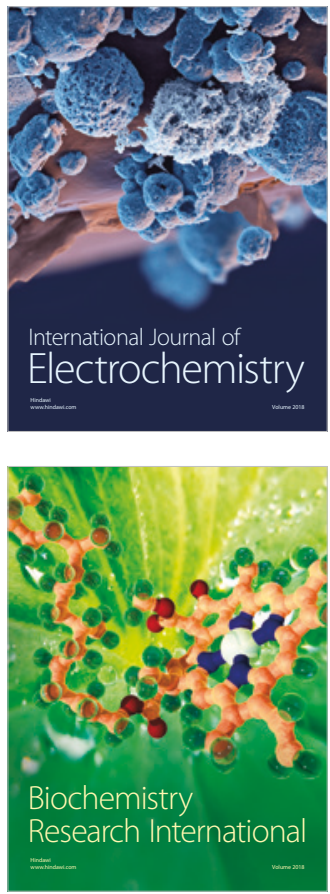